\title{
WestVirginiaUniversity
}

THE RESEARCH REPOSITORY @ WVU

Graduate Theses, Dissertations, and Problem Reports

2012

\section{Uncertainty Considerations with the GRIM}

Eric L. Everts

West Virginia University

Follow this and additional works at: https://researchrepository.wvu.edu/etd

\section{Recommended Citation}

Everts, Eric L., "Uncertainty Considerations with the GRIM" (2012). Graduate Theses, Dissertations, and Problem Reports. 436.

https://researchrepository.wvu.edu/etd/436

This Thesis is protected by copyright and/or related rights. It has been brought to you by the The Research Repository @ WVU with permission from the rights-holder(s). You are free to use this Thesis in any way that is permitted by the copyright and related rights legislation that applies to your use. For other uses you must obtain permission from the rights-holder(s) directly, unless additional rights are indicated by a Creative Commons license in the record and/ or on the work itself. This Thesis has been accepted for inclusion in WVU Graduate Theses, Dissertations, and Problem Reports collection by an authorized administrator of The Research Repository @ WVU. For more information, please contact researchrepository@mail.wvu.edu. 


\title{
Uncertainty Considerations with the GRIM
}

\author{
Eric L. Everts \\ Thesis submitted to the \\ Eberly College of Arts and Sciences \\ at West Virginia University \\ in partial fulfillment of the requirements \\ for the degree of \\ Master of Science in Forensic Science \\ Suzanne Bell, Ph.D., Chair \\ Keith Morris, Ph.D. \\ Patrick Buzzini, Ph.D.
}

Forensic and Investigative Science Program

Morgantown, West Virginia 2012

Keywords: Forensic science; glass; refractive index; uncertainty

Copyright 2012 Eric L. Everts 


\title{
ABSTRACT
}

\section{Uncertainty Considerations with Glass Refractive Index}

\author{
Eric L. Everts
}

Refractive index has been chosen as a comparison technique in glass analysis for many years. Hidden in this comparison is a quantitative measurement that requires the assessment of uncertainty. In this experiment, refractive index was performed on 63 samples from 41 sources of glass. Pairwise comparisons were calculated to illustrate the difference between using a conventional approach like standard deviation to using uncertainty. The amount of pairwise comparisons more than tripled from standard deviation to uncertainty showing the need to consider all possible sources of uncertainty in a refractive index measurement. 


\section{$\underline{\text { Table of Contents }}$}

TABLE OF CONTENTS

LIST OF FIGURES

INTRODUCTION

BACKGROUND

METHODS

RESULTS

DISCUSSION

CONCLUSION

APPENDIX A

APPENDIX B

33

REFERENCES

34 


\section{$\underline{\text { Table of Figures }}$}

Figure 1: Snell's Law 3

Figure 2: Screen shot of GRIM software $\quad 8$

Figure 3: Frequency of RI values of float glass samples in this experiment 10

Figure 4: Box plot of all samples and their RI 11

Figure 5: Box plot of samples and their RI re-plotted 12

Figure 6: Box plot of 3 different samples of a picture frame 13

Figure 7: Box plot of 3 different samples of PGZ glass 13

Figure 8: Box plot of 3 different samples of Burlap 14

Figure 9: Uncertainty budget for 1 of the 41 sources 17

Figure 10: Percent relative contribution of all factors for each source $\quad 20$

Figure 11: Pairwise comparisons for uncertainty of $k=2$

Figure 12: Pairwise comparisons for standard deviation 22

Figure 13: Pairwise comparisons for uncertainty of $k=1$ 


\section{$\underline{\text { Introduction }}$}

Glass is a common form of physical evidence that is easily transferred. Glass samples can come from many sources like house windows, car windows, glass bottles, eye glasses, and glass fiber optics, to name a few. The most common glass encountered is soda lime glass which is found in house windows and glass bottles (1). The next most common is laminated and tempered glass which comes from different windows in an automobile (1). Currently, the most common forensic analysis method for glass is the determination of refractive index (RI) (2). This technique has evolved from being manual with use of the Becke line method to current automated methods with the GRIM (Glass Refractive Index Measurement). Each type of glass can have a different RI based on its composition but the RI range for glass is narrow, typically a range from 1.47351.5600 (1). Because this range is so narrow, RI alone is often of limited value for discrimination and other techniques are needed (3). The techniques of X-ray fluorescence (XRF), inductively coupled plasma mass spectrometry (ICP-MS), and scanning electron microscope energy dispersive X-ray spectrometry (SEM-EDX), have shown promise as supplemental techniques to RI (2).

The National Academy of Sciences issued a report in 2009 (4) regarding the use of uncertainty when reporting a quantitative measurement. Thus, even though RI is used for comparison, it is a quantitative method. As such, the uncertainty of that measurement must be known to insure the utility and reliability of the data. To address this, an uncertainty budget will be created in this project and utilized in the results to show the effect that it does have. 


\section{Background}

The formation of glass is a multi-step process. All the materials that are used in forming the glass are combined, heated, and then cooled extremely quickly. Some of the main components in a glass sample are sand, soda, lime, and other elements that are more distinct to the individual company that is producing the glass. Glass can be formed into many shapes and sizes based on the type of glass and size needed. Soda lime glass is the most common contributing to house windows and glass bottles. Windshields are formed from two pieces of soda lime glass with a plastic sheet in between the layers, called laminated glass. One of the final forms of glass is tempered glass. Tempered glass is designed so that when it breaks it does so into small little pieces. This is advantageous for automobile windows as a safety feature. The production of these types of glass, flat glass and container glass, can be done through the processes of blowing, casting,

pressing, or spinning (1). Problems with the striations in flat glass due to the rolling were resolved by the float process. In the float process the liquid glass slides down onto a molten layer of tin or nickel and "floats" on it until it hardens. This is the primary way in which flat glass is produced in the United States (1).

$\mathrm{RI}$ is the main way in which glass is differentiated in forensic science (2). RI is a non-destructive technique that has generally been accepted as having sufficient accuracy and precision for casework (2). Refractive index is based on the concept that as light passes from one medium to another, it changes direction, wavelength, and speed due to the composition of that medium. Using Snell's Law (Figure 1) and knowing the angle, 
velocity, or RI of the first medium, the RI can be calculated for the second medium, which is this case is glass.

$$
\begin{gathered}
\frac{\sin \theta_{1}}{\sin \theta_{2}}=\frac{v_{1}}{v_{2}}=\frac{n_{2}}{n_{1}} \\
\text { Figure 1: Snell's Law }
\end{gathered}
$$

There are a number of ways to measure RI like automated or manual temperature variation or the Becke line method, to name a few (5). The second method of the Becke line involves a set of calibrated immersion liquids in which the analyst training and expertise are huge factors. The analyst starts by immersing the glass in the liquid and places it under the microscope. A bright "halo ring" or Becke line appears around the glass sample and as the focus of the microscope changes so does the location of the Becke line (5). This change, either movement toward the glass or the oil, indicates whether the glass has a higher or lower RI than the oil. The contrast between the oil and the glass then tells the analyst the magnitude of the difference. After this is performed, the glass is removed from the oil, cleaned, and placed in the next oil that is believed to be closer in RI based on the previous results. This procedure is repeated until the match point has been reached or it has been bracketed by two different oils (5). A plot of the results can then be made to determine the RI of the glass.

The first method above of temperature variation was perfected with the creation of the GRIM. It is based on similar principles but is carried out differently. The GRIM utilizes an immersion oil that changes refractive index as a function of temperature. The glass however changes very little with temperature, so when the glass "disappears" in the oil or the glass and oil have the least amount of contrast, the oil and glass have the same 
RI (5). These oils are calibrated using glass standards and the temperature can then be converted to an RI using the calibration curve.

Each type of glass produced has a different range of refractive indices and the refractive index range for those types of glasses are narrowing as the production processes are shrinking as manufacturing becomes more uniform. RI can also vary within a single sample (such as within a pane of window glass) because glass does not have a distinct crystal structure and is not homogeneous, especially float glass (6). As a result of glass not being homogeneous and becoming more similar in manufacturing, further classification by other techniques such as elemental analysis is often needed.

Techniques such as $\operatorname{XRF}(7,8)$ and $\operatorname{SEM}-\operatorname{EDX}(9,10)$ are two methods used to perform elemental analysis on glass. XRF and EDX allow for elemental analysis through bombarding the sample with an electron beam, X-ray beam, or another excitation source. When a sample is bombarded, the electrons or X-rays interact with the sample and can cause the ejection of one of the electrons in the shells of the atoms present. This causes an electron hole in which another election from a higher energy level of that atom falls "down" to fill the hole. When this happens, characteristics X-rays are emitted from the atom to release the energy between the higher and lower energy levels. These X-rays are then measure and collected by the detector. Elemental analysis can be gathered from this data because the X-rays emitted are specific to the atoms present and the quantities of the X-rays are reflective of the abundance of the atom in the sample.

There are many other techniques however that are used to determine the elemental analysis of glass. Some of these techniques are atomic absorption, inductively coupled plasma atomic emission spectrometry (ICP-AES), inductively coupled plasma mass 
spectrometry (ICP-MS), and laser ablation inductively coupled plasma mass spectrometry (LA-ICP-MS). The latter two techniques, ICP-MS and LA-ICP-MS, provide the most information regarding the elemental analysis of glass. One of the main advantages of these two techniques is the ability to detect isotopes of elements at low limits of detection (2). The main disadvantage of the ICP-MS is the destructive nature of the sample. The sample has to be crushed between low density polyethylene sheets and dissolved, heated and dried, and then dissolved again before putting into the instrument (9). LA is one way to counter this limitation. With LA, a small part of the sample to be ablated away using a high energy laser. The small particles that are produced are carried away by an argon gas, taken to a column of heated plasma and separated into atoms, before being analyzed by a mass spectrometer. This is an advantage because not only is a small part of the sample being used, but less time is needed to prepare the sample. For these reasons, LAICP-MS is currently considered to be ideally suited for elemental analysis of glass (10). Many studies have been done showing different sampling strategies that work best for LA-ICP-MS including tests done regarding micro-homogeneity (3) and also sample size and shape considerations (11). Due to its high capital cost, LA-ICP-MS is not found in most crime laboratories even though it is the best technique for elemental analysis of glass. The primary method used for elemental analysis is SEM-EDX. 


\section{Materials and Methods}

Sixty three random samples from forty one sources of glass were gathered from a combination of local glass and window companies, beer bottles, and drinking glasses. RI analysis was performed on the samples using a Foster and Freeman GRIM 3 coupled to a Foster and Freeman TA-1 phase contrast microscope using a FP82HT Mettler Toledo hotstage. A 590 nanometer(nm) filter was used to narrow the wavelengths of light emitted by the light source. Kohler illumination and lighting was confirmed daily. The glass slides and cover slips used for the calibration and samples were cleaned using ethanol and deionized water.

The calibration was performed using the Locke B oil, $590 \mathrm{~nm}$ light, Locke glass standards, and the certified RI values for each standard based on the conditions above. A total of 6 measurements of each glass standard (B1-B12) were performed to create a calibration curve using a least squares method. According to the procedure recommended by Foster and Freeman, the calibration curve could be accepted once all the values fell within the accepted +/- 10 maximum dri (deviation from RI) range. The FBI recommends calibrating using only a select set of the B1-B12 standards due to inconsistent responses close to room temperature. However in this study, all of the standards were used and in all cases, the dri maximum was within $+/-10$ dri. Once the calibration curve was within the acceptable limits, it was used to analyze the glass samples. At the start of each day of measurement, the microscope was turned on for an hour before any measurements were taken to allow for the area around the microscope to be heated to the temperature it would be at for the measurements. A glass standard was analyzed each day to make sure that the GRIM was working properly and that the RI fell 
within two standard deviations of the calibration curve for that standard to measure for any day-to-day variation.

All of the samples were first rinsed using deionized water and then crushed into smaller pieces using a mortar and pestle. The samples and standards were then prepared by placing a drop of the B oil on the cleaned slide and then placing a small piece of the desired glass in the B oil and crushing in into even smaller pieces on the slide. A cover slip was then placed on top of the sample and oil and placed in the hot stage that was placed on the microscope. The location of the glass from each sample used for this RI analysis, whether it be from the bulk of the sample or edge, was not considered here as in casework there may not be the ability to have this knowledge or choice.

Eight RI measurements were taken for each sample to get a representative sampling of the glass while making sure the edge count value for each measurement was acceptable. The GRIM converts the contrast between the oil and the glass edge to counts, the higher number the better, and this gives an indication of how distinct the edge was for contrast analysis. The average RI for each measurement was taken by averaging the cool-down and heat-up RI value. A screen shot of the analysis of a standard is below in Figure 2. The upper left box indicated by the green arrow is the view from the microscope to select the class samples for analysis. The colors/numbers of the points selected coincide with the graphs of the heating and cooling process to the right of the microscope view. The graphs are a measure of temperature versus contrast between the oil and glass. 


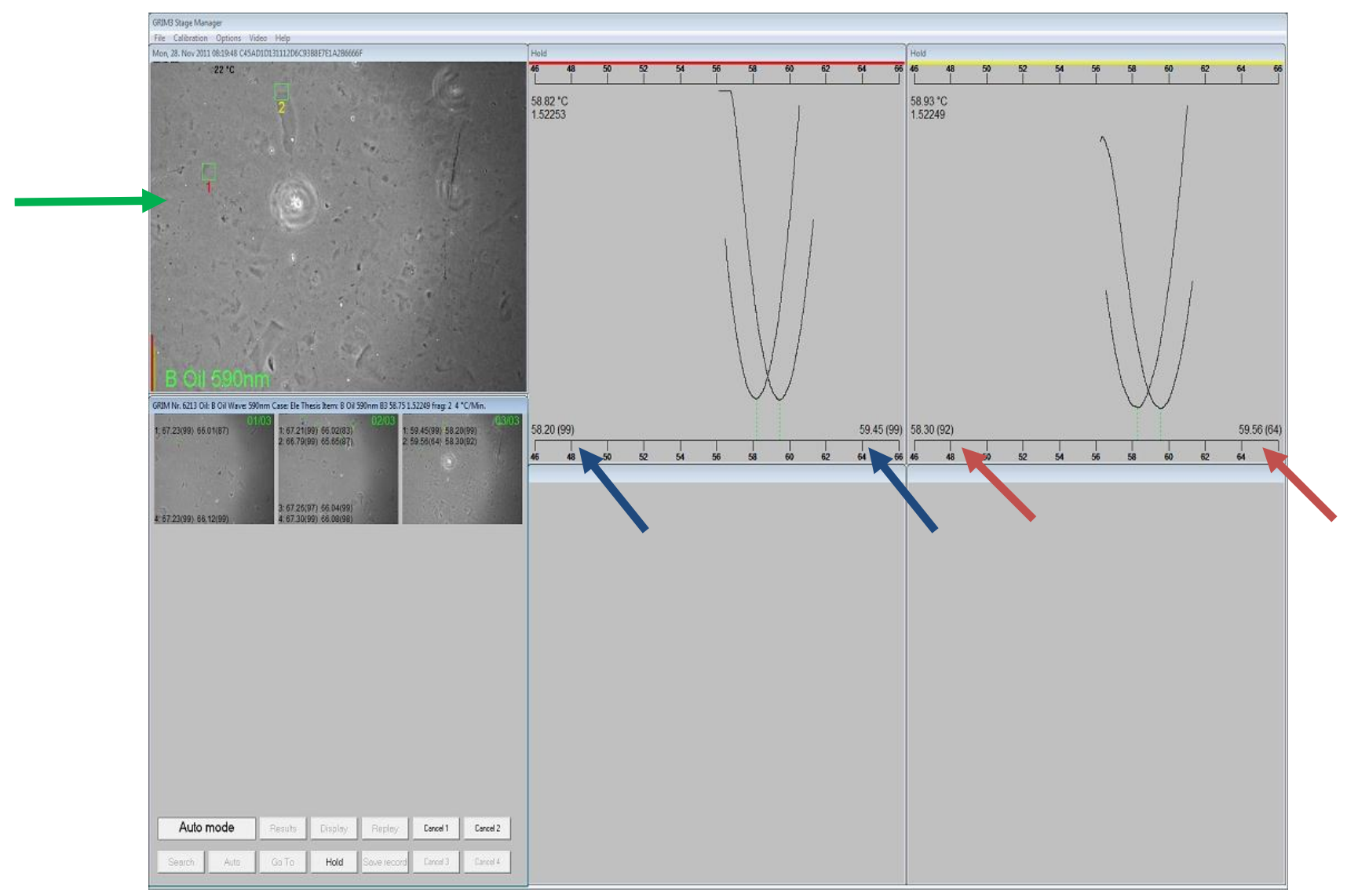

Figure 2: Screen Shot of GRIM software

In the lower left and right corner of each of those boxes, indicated by the blue and red arrows, are the heating and cooling RI values. The value in parenthesis that follows the RI value indicates the edge count value described above, with 99 being the highest and 1 the lowest. This is the reason for the use of a phase contrast microscope. The difference in contrast between the glass and oil is measured to determine when the glass and oil have the same RI and a phase contrast microscope is needed to distinguish these minute differences. If the curve does not yield an edge count of 99 then the curve will be smoothed and not as pointed at the lowest point. This does not allow for a minimum 
contrast to be determined between the oil and glass and thus it was not accepted as being an accurate RI value. The red arrows show a value that was rejected and not used as it did not produce edge counts of 99 for both values, where the blue arrows indicate an acceptable measurement 


\section{$\underline{\text { Results }}$}

All of the RI measurements for each sample and source are listed in Appendix A.

Figure 3 shows the frequency of the RI measurements for flat glass samples in this experiment and shows that glass manufacturing is improving and as a result, the range of RI's seen in case samples is becoming smaller.

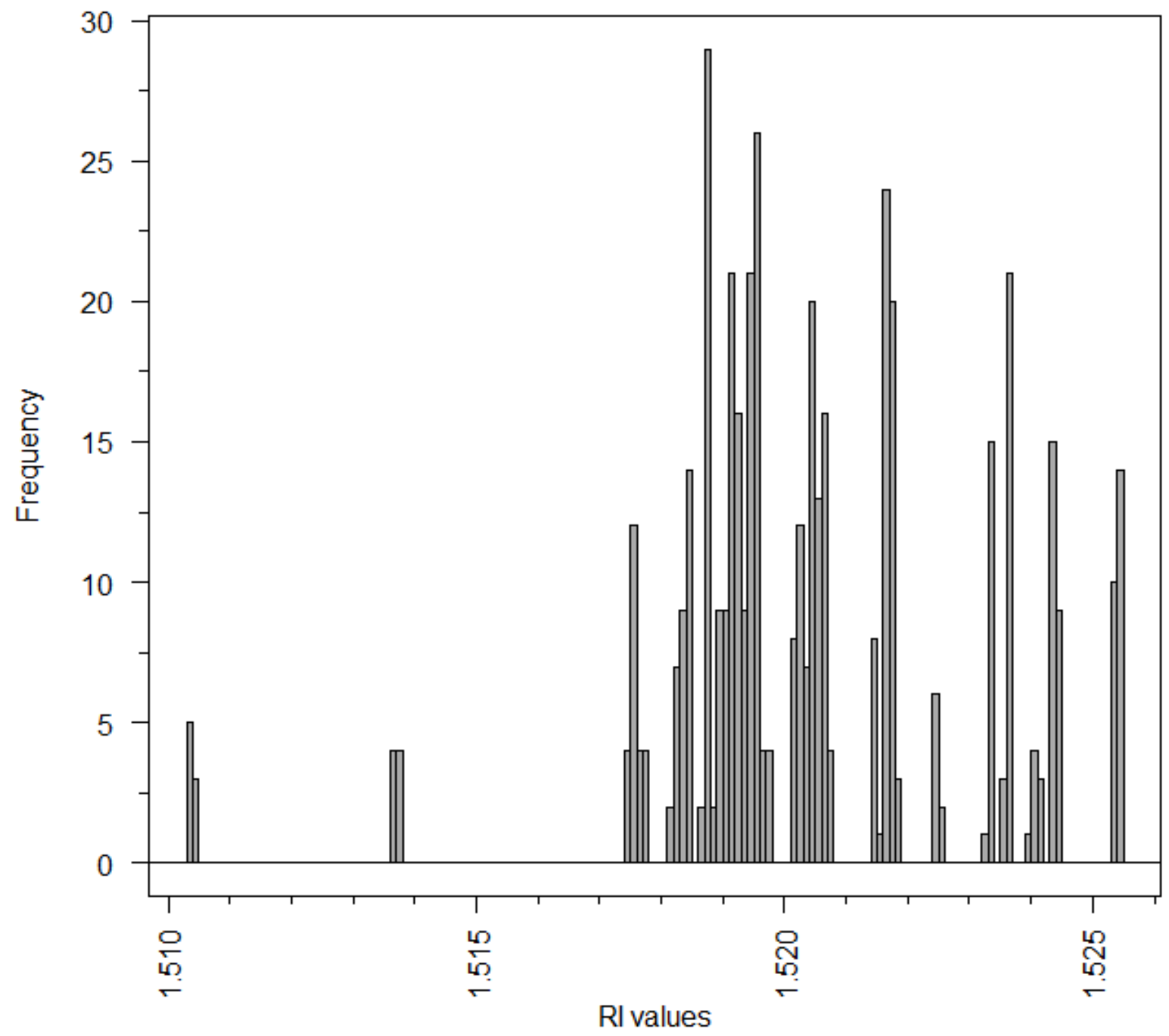

Figure 3: Frequency of RI values of float glass samples in this experiment 
This is a problem because as the expected range decreases, so does the ability to differentiate between glasses. These values are similar to the distribution of RI's that the FBI found in flat glass from 1980-1997. This database that the FBI created since the 1960's showed that the distributions of RI measurements have narrowed, and even though this study contains fewer sources than the FBI database, the same trends are seen (12). Figure 4 below illustrates a box plot of all of the samples and their average RI values.

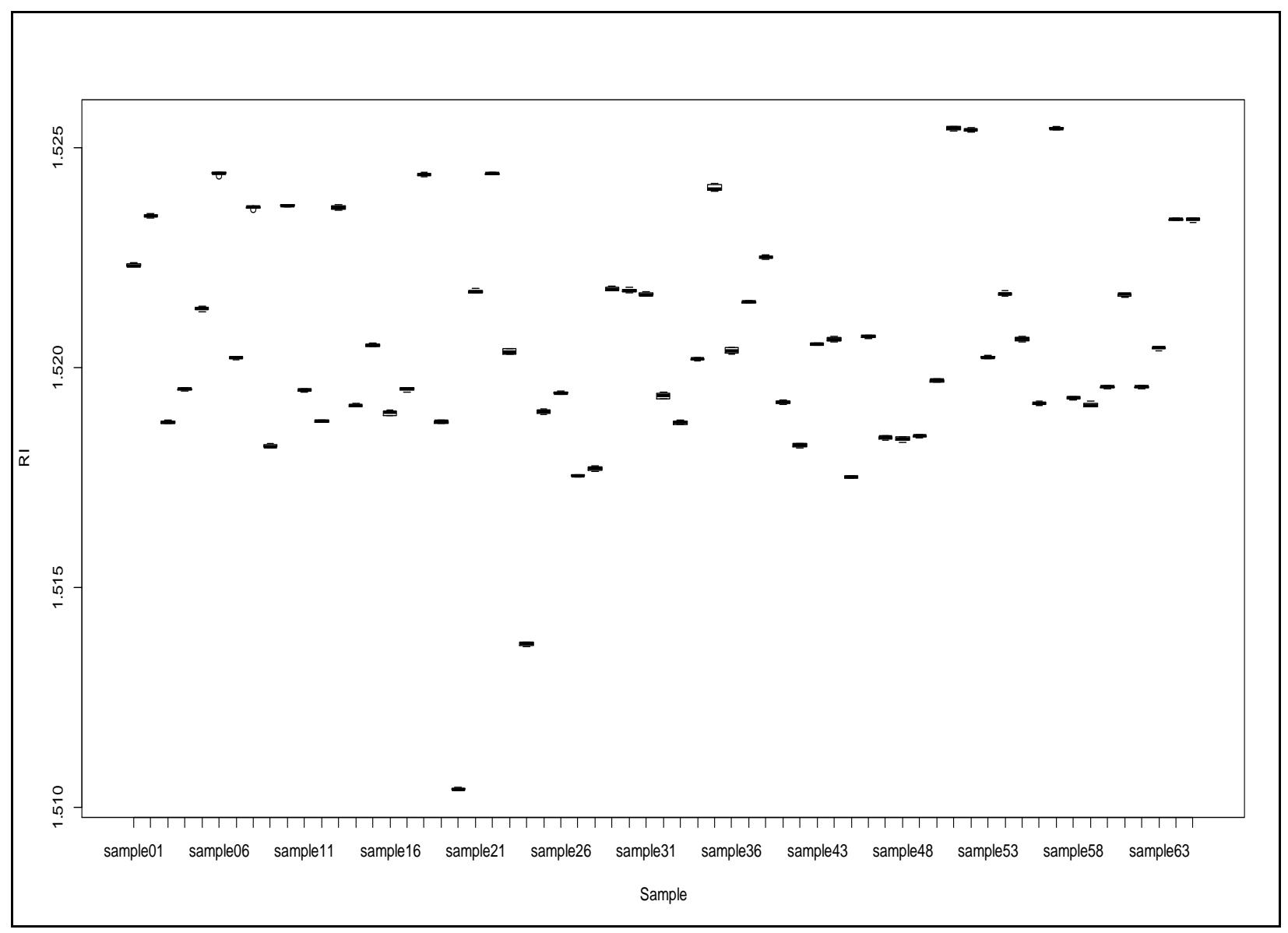

Figure 4: Box plot of all samples and their RI 
Given that sample 20 and 24 were much lower in RI than the rest of the bulk of the samples, the data is re-plotted in Figure 5 which shows the RI distribution of the bulk of the samples without those two included. These values in Figures 4 and 5 are the median and distribution of the 8 RI measurements taken for each sample. Some of these samples however are from the same source as there were 63 samples from only 41 sources.

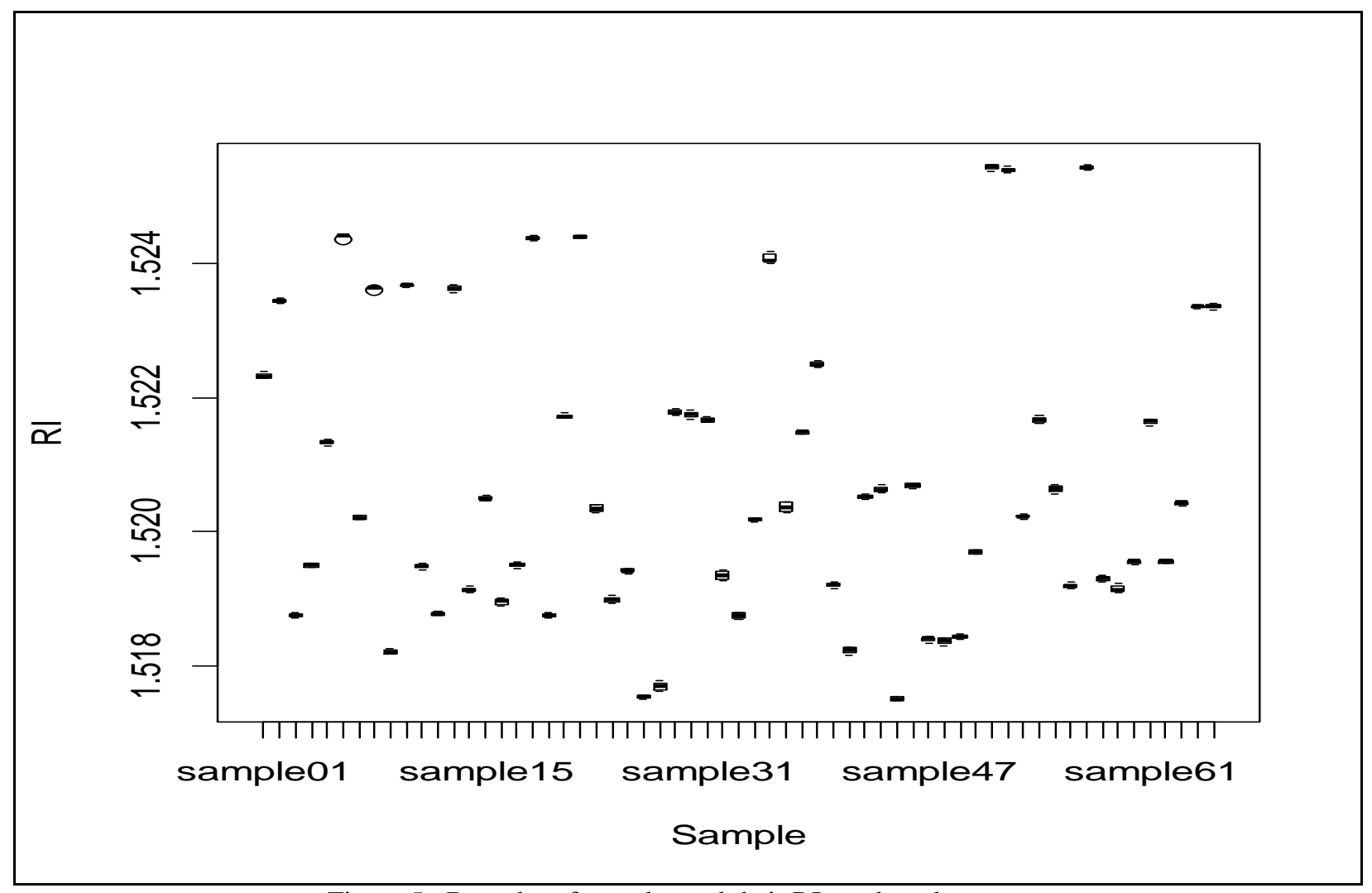

Figure 5: Box plot of samples and their RI re-plotted

Some of the sources of glass were sampled more than once to determine the homogeneity of the glass sources. Figures 6, 7, and 8 show a boxplot of 3 different sources of glass that were sampled 3 times. The box represents $25 \%$ to $75 \%$ of the RI values with the dark line in the center being the median RI value. 


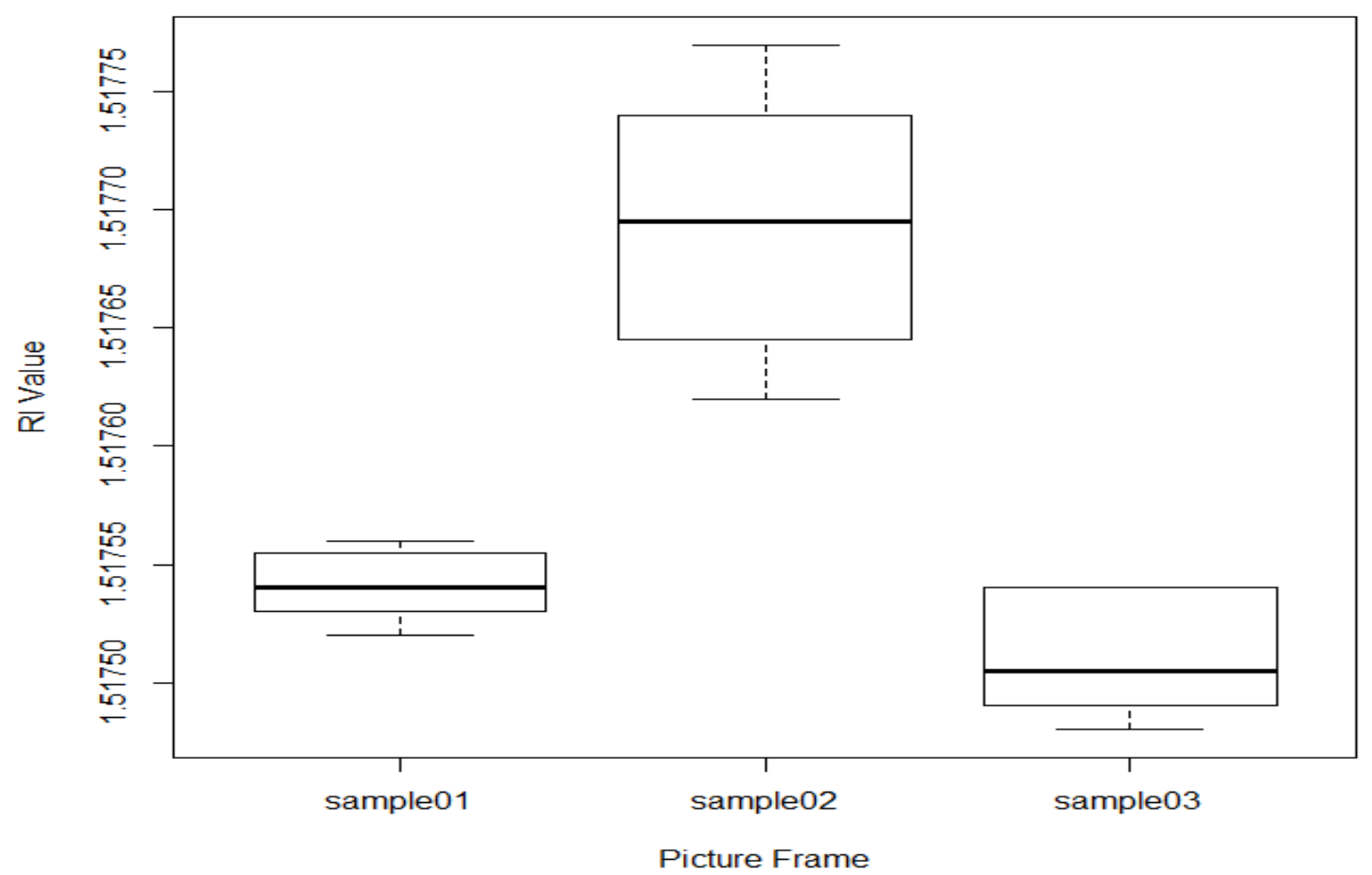

Figure 6: Box plot of 3 different samples of a picture Frame

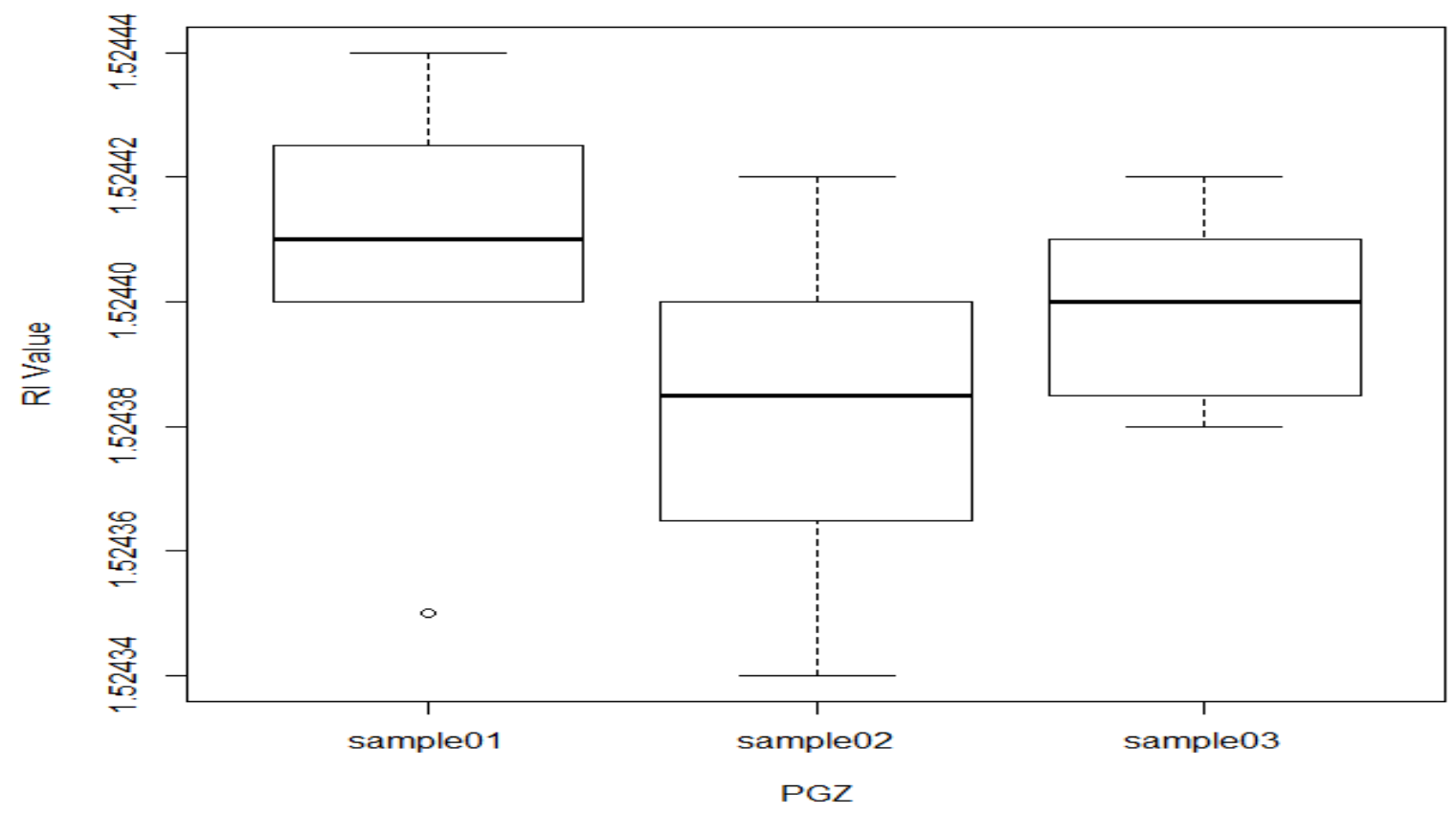

Figure 7: Box plot of 3 different samples of PGZ glass 
In Figure 6, which was glass from a South African picture frame, the distribution of the RI of the glass was larger than in any other sample. A t-test of the sample means assuming unequal variances showed that all 3 of the samples were statistically significantly different at the 95\% confidence level. However, in Figure 7, which was PGZ glass, all 3 samples were not found to be statistically significantly different using the same test. Figure 8, which was burlap glass, had a mixed result. Samples 1 and 3 were found to be from the same grouping according to the t-test while sample 2 was found to be statitistically significantly different at the $95 \%$ confidence than both samples 1 and 3. The amount of intrasample variation was different for each source of glass however the sources of glass where only one sampling took place did not have the ability to show this variability between samples.

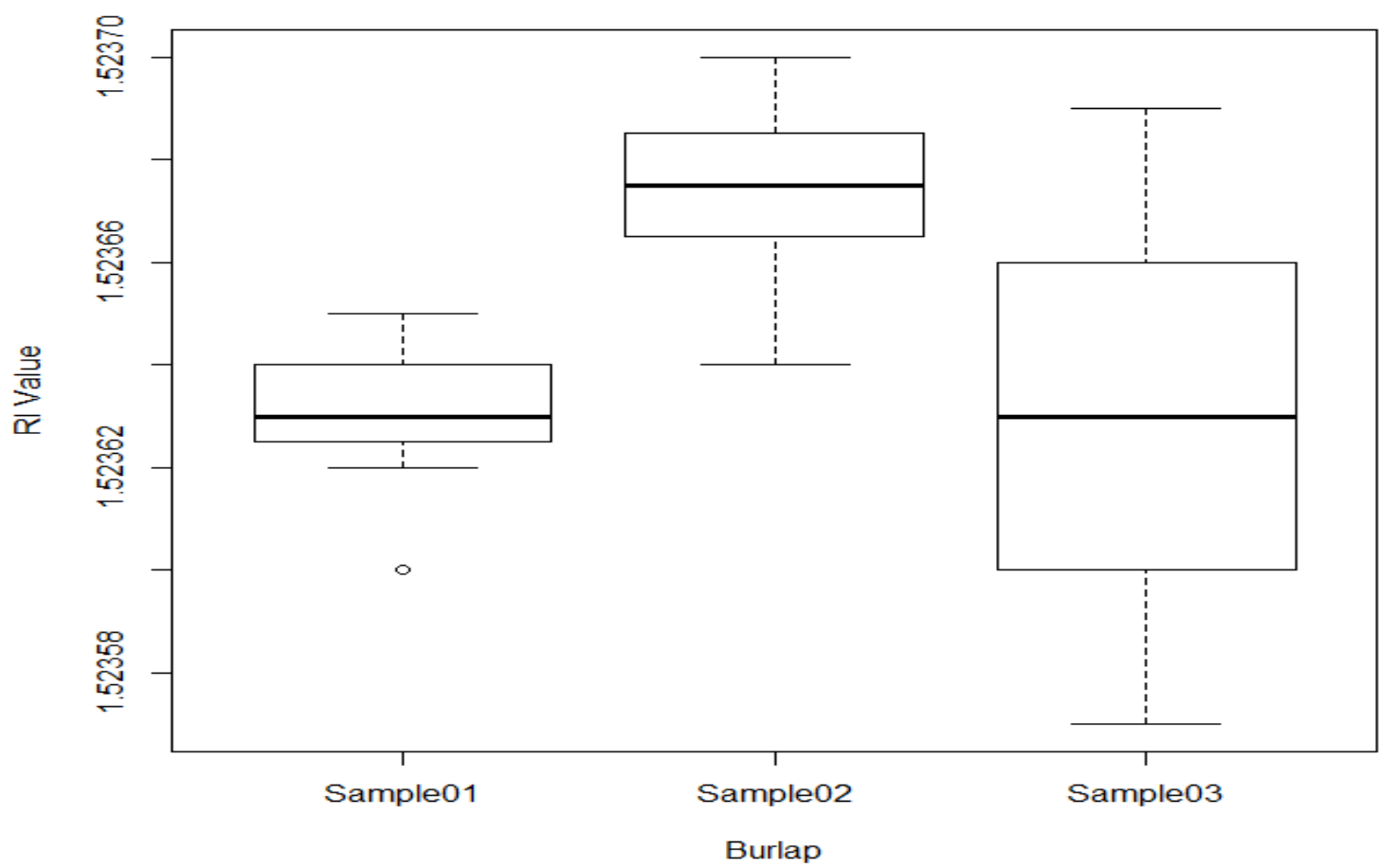

Figure 8: Box plot of 3 different samples of Burlap 
When RI determinations are performed using the oils and Becke line and not the GRIM, the RI is measured to 2 or 3 decimal places. Accordingly, if the samples in this study were evaluated using these methods, there would be no differentiation among any of the samples. With the ability of the GRIM to determine RI using 5 decimal places, the homogeneity of glass with regards to RI becomes a critical factor. This is shown in the glasses above where samples that are known to have come from the same source have statistically significantly different RI's and this further validates all of the previous studies about glass inhomogeneity (13). This presents the question of sampling and how many samples and measurements for a source of glass need to be performed to determine the range of RI values expected within a sample.

When a quantitative measurement is preformed, many factors contribute to the expected spread or uncertainty associated with that measurement. One method used to characterize this spread is to perform replicate measurements and calculate a standard deviation. However the standard deviation alone is an incomplete representation of the total uncertainty expected to be associated with an RI. Currently, the recommended standard for the estimation of uncertainty associated with a measurement is the ISO/BIPM Guide to the Expression of Uncertainty in Measurement (referred to as GUM or Guide) (14). The GUM provides a guideline for evaluating all the parameters that can affect a measurement value from start to finish. The first step is to develop a list of all the possible factors of uncertainty in the given measurement. These can come from many sources including the instrument and the operator. The Guide groups the uncertainty factors determined in two different groups, type A and type B uncertainty. Type A uncertainty have replicate measurements and are characterized by standard deviation and 
type B are those which are evaluated by other means (14). A value for each factor is determined based on the type of uncertainty. If the uncertainty is type A, then the standard deviation of that factor is known and is used as the value for that factor. The values for factors with type B uncertainty are based on scientific judgment using information based on the manufacturer, other data analyses and measurements, experience or general knowledge of the instrument and material, or even handbooks(15).

The next step is to determine the kind of distribution of each contributing factor. The distributions can be many different possibilities from normal to rectangular to triangular, to name a few. They type of distribution determines the divisor of the value assigned to the uncertainty factor. An example would be if the value assigned to an uncertainty factor was 5 and it was a rectangular distribution, the divisor of a rectangular distribution is the $\sqrt{3}$ so the uncertainty $(u)$ for that factor would be 5 divided by the $\sqrt{3}$. The need for the divisor is to allow for all of the factors to be adjusted so that they are expressed as standard deviation units.

Once the uncertainty contribution for each factor has been estimated, the combined uncertainty for the system or measurement is estimated by taking the square root of the sum of the squares of each factor's uncertainty. This number can then be multiplied by a specific coverage factor to determine the expanded uncertainty. A coverage factor of 2 or 3 is generally chosen where 2 is equivalent to $95 \%$ confidence and 3 is equivalent to $99 \%$ confidence.

Many areas of science have already adopted the idea of expressing uncertainty in measurement from areas in chemistry like neutron activation analysis (16), to social psychology (17), to analytical method validation (18). In the NAS report, any laboratory 
that was performing quantitative analysis was encouraged to use uncertainty with their measurements and results (4). For this research the uncertainty factors that were considered were the uncertainty with the calibration curve, the day to day variation, and the sample variation. Figure 9 is an example of an uncertainty budget for one of the 41 sources of glass.

\begin{tabular}{|l|r|l|l|l|l|l|l|}
\hline Factor & Value $(\mathrm{x})$ & Distribution & Divisor & $\mathrm{u}$ & $\mathrm{u} 2$ & $\begin{array}{l}\text { \%Relative } \\
\text { contribution }\end{array}$ & \\
\hline & & & & & & & \\
\hline Calibration & 0.0001 & Rectangular & 1.73 & $5.77 \mathrm{E}-05$ & $3.33 \mathrm{E}-09$ & 63.28 & \\
\hline day-to-day & 0.00006 & Rectangular & 1.73 & $3.46 \mathrm{E}-05$ & $1.20 \mathrm{E}-09$ & 22.78 & \\
\hline $\begin{array}{l}\text { Within- } \\
\begin{array}{l}\text { Sample } \\
\text { variation }\end{array}\end{array}$ & $2.71 \mathrm{E}-05$ & Normal & 1 & $2.71 \mathrm{E}-05$ & $7.34 \mathrm{E}-10$ & 13.94 & \\
\hline & & & & & & & \\
\hline & & & & sum & $5.27 \mathrm{E}-09$ & & \\
\hline & & & & $\begin{array}{l}\text { Square } \\
\text { root }\end{array}$ & $4.4 \mathrm{E}-05$ & & \\
\hline & & & & & & & \\
\hline & & & & k=2 & $8.8 \mathrm{E}-05$ & & \\
\hline
\end{tabular}

Figure 9: Uncertainty Budget for 1 of the 41 sources

The uncertainty factors are listed with the value assigned to that factor next to it. The calibration and day-to-day variation were treated as rectangular because they had an equal probability of being anywhere $+/$ - the value listed from the mean. A normal distribution which was assigned to the within-sample variation, has a divisor of 1 while a rectangular has a divisor of $\sqrt{ } 3$. The values of the uncertainty for each factor are listed under the column $\mathrm{u}$ with the next column being the square of the uncertainty for each factor. All of the uncertainties were then added to calculate the $\%$ relative contribution to the overall uncertainty. There are differing opinions as to the elimination of certain factors that contribute to the overall uncertainty based on this percentage. For this 
research, all of the percent contributions were greater than $10 \%$ except for one, and all factors were considered when calculating the overall uncertainty.

The calibration uncertainty and day-to-day uncertainty remained constant throughout each budget for each sample as all the samples were based on the same calibration curve and well as run on the same instrument with the same day-to-day variation. The sample variation or within sample repeatability was dependent on the source of glass and could be the result of anywhere from 8-24 measurements depending on the source.

Figure 10 lists the percent relative contribution for each factor as well as the number of measurements for each source. After the uncertainty for each source was calculated, the square root of the squares of each factor was used to calculate the overall uncertainty. A coverage factor of $\mathrm{k}=2$ was used to express a $95 \%$ confidence of uncertainty for each source for that RI.

A pairwise comparison was then performed on all of the sources to be able to determine what samples could or could not be eliminated from each other based on the $95 \%$ confidence achieved through the uncertainty budget. Figure 11 shows the list of all the pairwise comparison of all the sources against one another. A total of 820 comparisons were made and 82 of those 820 produced an overlap in RI's and thus a need to do further analysis. For example, if a piece of glass from group 1 was chosen, the only group that had a "yes" result was group 33. This means that when considering the +/range of group 1, only group 33 of the 41 sources had a +/- range that overlapped according to the $95 \%$ confidence in the uncertainty result. Figures 12 and 13 show what the pairwise comparisons would have looked like had it been based on just the standard 
deviations of the samples without any uncertainty and then $68 \%$ confidence or $\mathrm{k}=1$, respectively. If the same analogy is used as above, then group 1 would have yielded no overlap between any of the other sources in either case. In the same way, if a random piece of glass was chosen from the set of forty one sources without replacement, the highest number of pairwise comparisons according to just the standard deviation would have been 3 for group/source 11, as seen in Figure 12. If that same sample was drawn at random without replacement and the uncertainty value with a $95 \%$ confidence value was used, the number of pairwise comparisons would have been 7 . This is a significant difference in that the number is more than double what it would have been originally had uncertainty not been taken into account.

When a quantitative measurement such as RI is taken, a mean and standard deviation is obtained. However, if the standard deviation alone is used to establish uncertainty, it could lead to a false positive result where a piece of glass could be excluded when in fact it should be included. The results in Figures 11-13 show that there is a notable difference between the number of pairwise comparisons that would have been done had the analysis just been done solely on the standard deviation of the RI measurements and not based on the uncertainty to $95 \%$. The number increases from a total of 18 pairwise comparisons to 74 . 


\begin{tabular}{|c|c|c|c|c|c|c|c|c|c|c|c|c|c|c|}
\hline & Group 1 & Group 2 & Group 3 & Group 4 & Group 5 & Group 6 & Group 7 & Group 8 & Group 9 & Group 10 & Group 11 & Group 12 & Group 13 & Group 14 \\
\hline Calibration & 64.75 & 59.22 & 56.55 & 58.1 & 64.31 & 50.83 & 57.32 & 33.35 & 38.51 & 60.74 & 37.33 & 61.42 & 50.62 & 26.35 \\
\hline Day to Day & 23.31 & 21.32 & 20.36 & 20.92 & 23.15 & 18.3 & 20.64 & 12.01 & 13.86 & 21.87 & 13.44 & 22.11 & 18.22 & 9.49 \\
\hline Repeatability & 11.95 & 19.46 & 23.1 & 20.99 & 12.54 & 30.88 & 22.04 & 54.64 & 47.62 & 17.4 & 49.23 & 16.47 & 31.16 & 64.17 \\
\hline $\mathrm{n}=$ & 24 & 24 & 24 & 24 & 16 & 16 & 24 & 16 & 16 & 16 & 16 & 24 & 24 & 24 \\
\hline & Group 15 & Group 16 & Group 17 & Group 18 & Group 19 & Group 20 & Group 21 & Group 22 & Group 23 & Group 24 & Group 25 & Group 26 & Group 27 & Group 28 \\
\hline Calibration & 57.53 & 62.02 & 54.35 & 62.16 & 59.7 & 61.28 & 62.56 & 47.06 & 66.14 & 58.03 & 53 & 52.3 & 63.21 & 56.26 \\
\hline Day to Day & 20.71 & 22.33 & 19.57 & 22.38 & 21.49 & 22.06 & 22.52 & 16.94 & 23.81 & 20.89 & 19.08 & 18.83 & 22.76 & 20.25 \\
\hline Repeatability & 21.75 & 15.65 & 26.09 & 15.47 & 18.8 & 16.66 & 14.92 & 36 & 10.05 & 21.08 & 27.92 & 28.87 & 14.03 & 23.48 \\
\hline $\mathrm{n}=$ & 8 & 8 & 8 & 8 & 8 & 8 & 8 & 8 & 8 & 8 & 8 & 8 & 8 & 8 \\
\hline & Group 29 & Group 30 & Group 31 & Group 32 & Group 33 & Group 34 & Group 35 & Group 36 & Group 37 & Group 38 & Group 39 & Group 40 & Group 41 & \\
\hline Calibration & 51.46 & 41.1 & 52.44 & 65.85 & 37.33 & 37.67 & 66.9 & 56.76 & 57.61 & 53.14 & 62.22 & 50.27 & 63.28 & \\
\hline Day to Day & 18.52 & 14.8 & 18.88 & 23.7 & 13.44 & 13.56 & 24.08 & 20.43 & 20.74 & 19.13 & 22.4 & 18.1 & 22.78 & \\
\hline Repeatability & 30.02 & 44.1 & 28.68 & 10.45 & 49.23 & 48.77 & 9.02 & 22.81 & 21.66 & 27.72 & 15.38 & 31.63 & 13.94 & \\
\hline $\mathrm{n}=$ & 8 & 8 & 8 & 8 & 8 & 8 & 8 & 8 & 8 & 8 & 8 & 8 & 8 & \\
\hline
\end{tabular}

Figure 10: Percent relative contribution of all factors for each source 


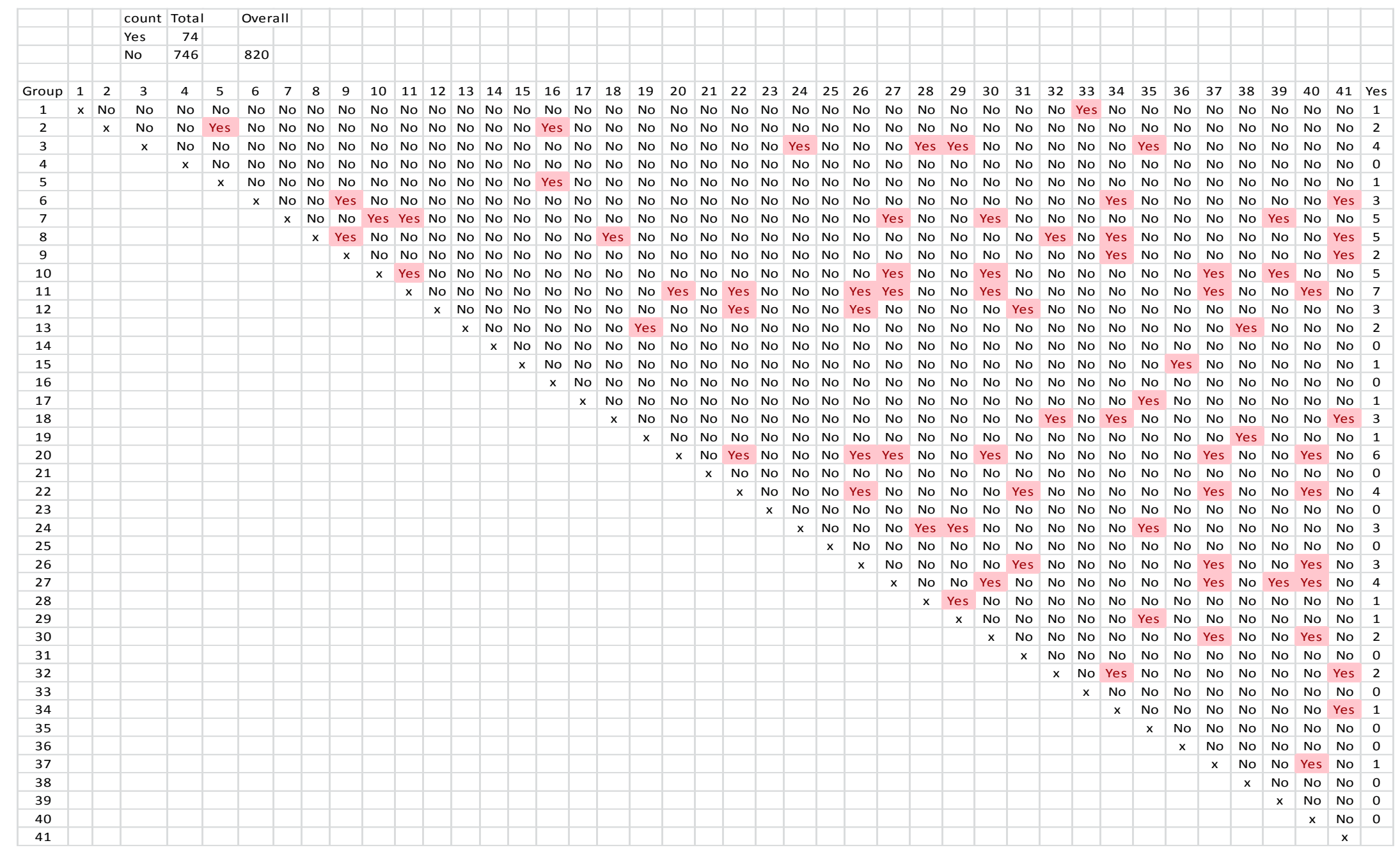

Figure 11: Pairwise comparison for uncertainty of $\mathrm{k}=2$ 


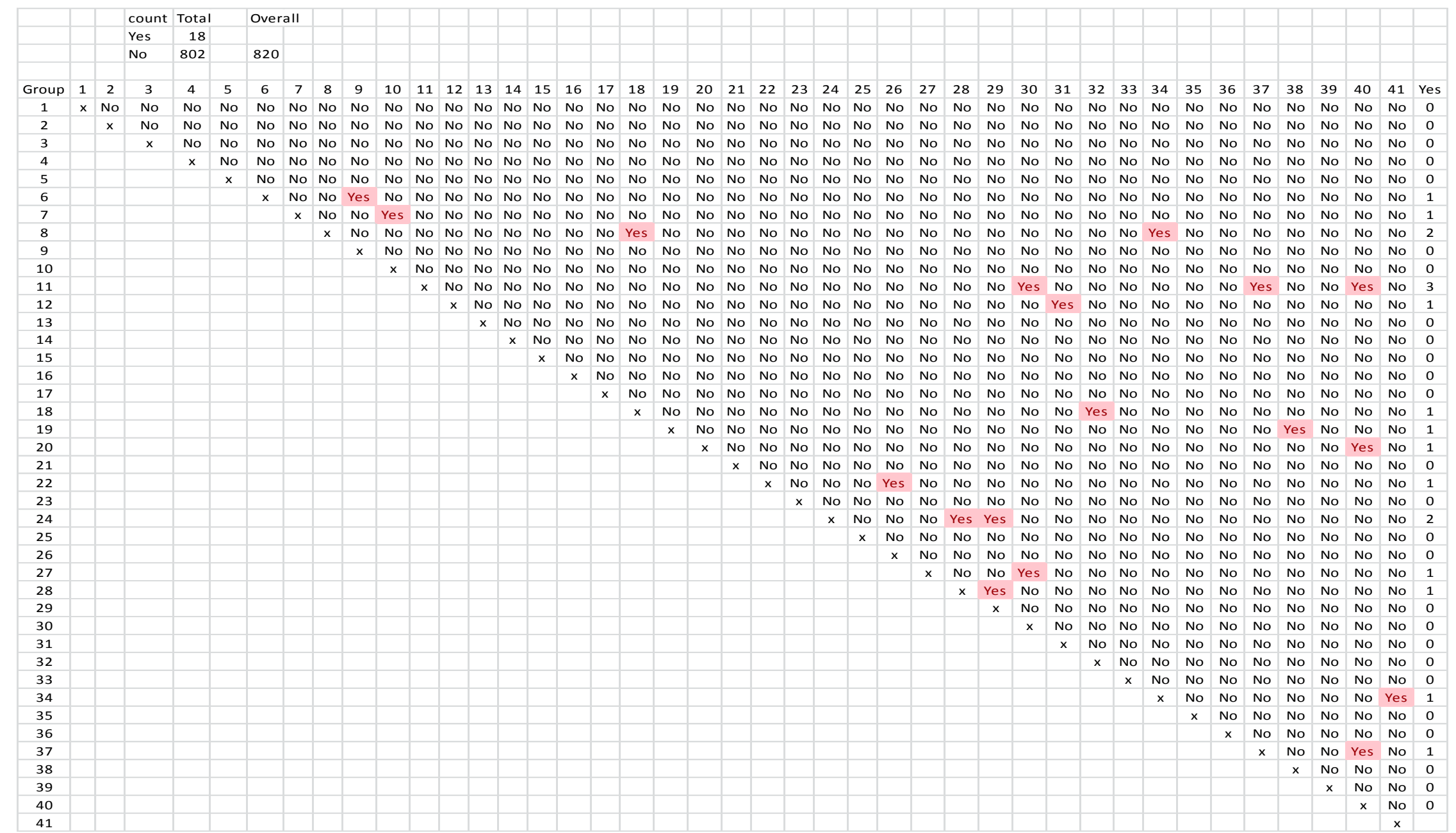

Figure 12: Pairwise comparison of standard deviation 


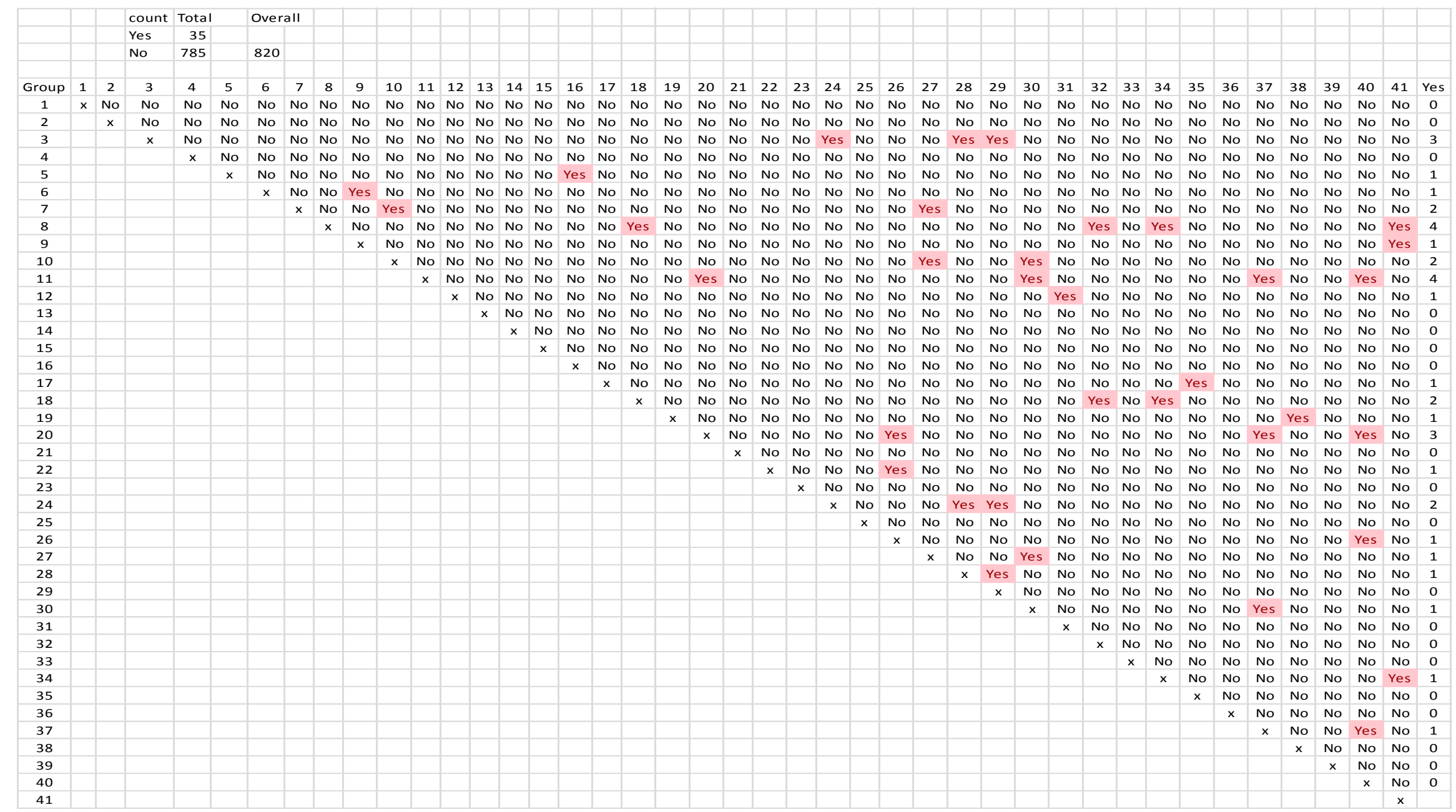

Figure 13: Pairwise comparison for uncertainty of $k=1$ 
The categories of glass used in this study were window glass, which was the type of glass made for a house or building window, bottle glass, which was from a glass bottle, car window glass, which came from the side or rear windows, laminated glass, which came from windshields or other glass that needed to be laminated, and drinking glass, which was from drinking glasses. Appendix B shows a boxplot of all of the RI's for each of these categories of glass. T-tests of means assuming unequal variances were performed again for the three largest categories of glass; bottle, window, and car window. Of these three groups, only the car window and window glass were statistically significantly different. If a random piece of glass was found that had a RI of 1.52125 for example, it could be from any one of those 3 main categories. A probability however could be assessed as to the likelihood of the glass being from each one of the categories based on the RI. 


\section{$\underline{\text { Discussion }}$}

When statistical tests were performed on the 3 major categories of glass, only car windows and windows were found to have a statistically significant difference. However, even though they were found to be statistically significantly different, there was overlap in the range of possibilities of RI's for all 3 of these categories. This significant difference does not correlate to the groups being from different sources however. This all is discouraging for forensic glass analysts because if glass of unknown origin is recovered on a suspect, RI may not give an indication as to the type of glass it is unless a probability of occurrence is used. Although this set of 41 sources does not comprise all of the possible sources that one could encounter in casework, the major categories of glass are present. This is also a smaller sample size compared to the larger picture but the same types of trends are found here that is seen in the FBI study of float glass dating back to the 1960 's.

A procedure for assessing the sample variation/repeatability needs to be developed by each laboratory and guidelines to establishing an accurate measure of RI. The number of measurements can be different based on the type of glass and intra-sample variation of the source, but a procedure for determining when this is achieved is needed as the results of this experiment and past experiments show the intra-sample variations that can occur. In the past, RI measurements were out to three decimal places, however with the GRIM these measurements are now out to 5 decimal places. This increased precision however has presented the homogeneity problem and the need for a laboratory to develop a procedure for handling this. Bennett and Curran sum up numerous studies and perform their own study relating to the inhomogeneity of glass and how it can or 
can't vary from center to edge of the pane as well as the float or non-float side to the bulk of the glass (13). They also recommend the need to develop a procedure for sampling a known piece of glass in order to achieve proper sampling and an accurate RI measurement. This also raises another important question with casework when one shard of glass is recovered, can that shard be attributed to a source when only one set of measurements can be made? The intra-sample variation found here as well as with Bennett and Curran show that one set of 8 measurements may be insufficient.

All of the standard values for the calibration curve fell within the required dri values, however the highest dri value, which was used for the calibration part of the uncertainty budget, could have been reduced as it came from one of the standards that the FBI omits. Also, the day-to-day variation was the highest using one of the standards that tends to me omitted as well, so the day-to-day variation could be reduced using only the select standards to make the curve. For the purpose of creating a basic fundamental and conservative approach to uncertainty, all of the standards were used in making the calibration curve, including the standards that tend to cause a lot of problems for scientists. As a result, the $95 \%$ confidence values have the opportunity to be reduced, however to what extent would need to be further studied.

Refractive index is traditionally thought of as a classification method and in reality it is, however underneath this source determination is a quantitative measurement. As a result of good analytical practice and the NAS report, uncertainty should be estimated for any RI measurement. Garvin and Koons recently completed a match criteria study using 8 different criteria for RI (19). It included options such as standard deviations and fixed ranges to determine the best way to compare RI of glass fragments 
taking into account the inhomogeneity of the glass but reducing false negatives (19). Uncertainty was not one of the match criteria options considered in this study. As seen in Figures 11-13, there is a difference in the number of pairwise comparisons when using just the standard deviation compared to assessing the uncertainty, and it is here that the problem lies. Had this have been casework and just the standard deviation was evaluated and used, false positives or exclusions would have been made. One might have concluded that based just on the standard deviation that two pieces of glass were from different sources when in reality they were from the same source and using the $95 \%$ confidence uncertainty would have shown that. Limiting the number false positives and false negatives was the goal of Garvin and Koons and should be the goal of every match criteria, however a laboratory would need to consider when it cannot eliminate both, which one it considers to be more important. 


\section{$\underline{\text { Conclusions }}$}

As the values show in this study, the impact of using an uncertainty budget and applying it RI, greatly affects the result that one might conclude when performing RI measurement. The inhomogeneity of glass and the problems that it can cause was further validated here. RI is looked at as a source determination and seldom acknowledged as quantification, but to make the source determination, the RI value needs to be determined. Each glass source had a different intra-sample variation and using match criteria of fixed intervals and just a standard deviation does not account for all the possible variations. The ability of uncertainty to cover all the factors associated with RI are seen here and need to be applied to all RI measurements in the future for both research and casework. 


\section{Appendix A}

\begin{tabular}{|c|c|c|c|c|c|c|c|c|}
\hline sample01 & run1 & 1.52231 & sample22 & run1 & 1.52440 & sample43 & run1 & 1.51754 \\
\hline sample01 & run2 & 1.52230 & sample22 & run2 & 1.52438 & sample43 & run2 & 1.51749 \\
\hline sample01 & run3 & 1.52237 & sample22 & run3 & 1.52442 & sample43 & run3 & 1.51749 \\
\hline sample01 & run4 & 1.52238 & sample22 & run4 & 1.52438 & sample43 & run4 & 1.51754 \\
\hline sample01 & run5 & 1.52230 & sample22 & run5 & 1.52441 & sample43 & run5 & 1.51751 \\
\hline sample01 & run6 & 1.52232 & sample22 & run6 & 1.52441 & sample43 & run6 & 1.51748 \\
\hline sample01 & run7 & 1.52229 & sample22 & run7 & 1.52440 & sample43 & run7 & 1.51750 \\
\hline sample01 & run8 & 1.52229 & sample22 & run8 & 1.52439 & sample43 & run8 & 1.51754 \\
\hline sample02 & run1 & 1.52346 & sample23 & run1 & 1.52035 & sample44 & run1 & 1.52071 \\
\hline sample02 & run2 & 1.52344 & sample23 & run2 & 1.52041 & sample44 & run2 & 1.52072 \\
\hline sample02 & run3 & 1.52343 & sample23 & run3 & 1.52030 & sample44 & run3 & 1.52072 \\
\hline sample02 & run4 & 1.52348 & sample23 & run4 & 1.52032 & sample44 & run4 & 1.52069 \\
\hline sample02 & run5 & 1.52341 & sample23 & run5 & 1.52041 & sample44 & run5 & 1.52065 \\
\hline sample02 & run6 & 1.52342 & sample23 & run6 & 1.52029 & sample44 & run6 & 1.52068 \\
\hline sample02 & run7 & 1.52340 & sample23 & run7 & 1.52041 & sample44 & run7 & 1.52065 \\
\hline sample02 & run8 & 1.52347 & sample23 & run8 & 1.52029 & sample44 & run8 & 1.52071 \\
\hline sample03 & run1 & 1.51877 & sample24 & run1 & 1.51368 & sample45 & run1 & 1.51835 \\
\hline sample03 & run2 & 1.51879 & sample24 & run2 & 1.51370 & sample45 & run2 & 1.51841 \\
\hline sample03 & run3 & 1.51871 & sample24 & run3 & 1.51375 & sample45 & run3 & 1.51840 \\
\hline sample03 & run4 & 1.51875 & sample24 & run4 & 1.51375 & sample45 & run4 & 1.51843 \\
\hline sample03 & run5 & 1.51872 & sample24 & run5 & 1.51365 & sample45 & run5 & 1.51841 \\
\hline sample03 & run6 & 1.51879 & sample24 & run6 & 1.51375 & sample45 & run6 & 1.51838 \\
\hline sample03 & run7 & 1.51875 & sample24 & run7 & 1.51366 & sample45 & run7 & 1.51843 \\
\hline sample03 & run8 & 1.51873 & sample24 & run8 & 1.51373 & sample45 & run8 & 1.51833 \\
\hline sample04 & run1 & 1.51948 & sample25 & run1 & 1.51896 & sample46 & run1 & 1.51841 \\
\hline sample04 & run2 & 1.51946 & sample25 & run2 & 1.51902 & sample46 & run2 & 1.51829 \\
\hline sample04 & run3 & 1.51951 & sample25 & run3 & 1.51898 & sample46 & run3 & 1.51835 \\
\hline sample04 & run4 & 1.51947 & sample25 & run4 & 1.51901 & sample46 & run4 & 1.51835 \\
\hline sample04 & run5 & 1.51950 & sample25 & run5 & 1.51893 & sample46 & run5 & 1.51842 \\
\hline sample04 & run6 & 1.51952 & sample25 & run6 & 1.51905 & sample46 & run6 & 1.51840 \\
\hline sample04 & run7 & 1.51952 & sample25 & run7 & 1.51902 & sample46 & run7 & 1.51841 \\
\hline sample04 & run8 & 1.51953 & sample25 & run8 & 1.51894 & sample46 & run8 & 1.51831 \\
\hline sample05 & run1 & 1.52134 & sample26 & run1 & 1.51943 & sample47 & run1 & 1.51845 \\
\hline sample05 & run2 & 1.52138 & sample26 & run2 & 1.51937 & sample47 & run2 & 1.51843 \\
\hline sample05 & run3 & 1.52128 & sample26 & run3 & 1.51941 & sample47 & run3 & 1.51840 \\
\hline sample05 & run4 & 1.52136 & sample26 & run4 & 1.51945 & sample47 & run4 & 1.51847 \\
\hline sample05 & run5 & 1.52137 & sample26 & run5 & 1.51942 & sample47 & run5 & 1.51841 \\
\hline sample05 & run6 & 1.52134 & sample26 & run6 & 1.51940 & sample47 & run6 & 1.51843 \\
\hline sample05 & run7 & 1.52134 & sample26 & run7 & 1.51945 & sample47 & run7 & 1.51844 \\
\hline sample05 & run8 & 1.52127 & sample26 & run8 & 1.51940 & sample47 & run8 & 1.51843 \\
\hline sample06 & run1 & 1.52441 & sample27 & run1 & 1.51751 & sample48 & run1 & 1.51967 \\
\hline sample06 & run2 & 1.52444 & sample27 & run2 & 1.51756 & sample48 & run2 & 1.51972 \\
\hline sample06 & run3 & 1.52444 & sample27 & run3 & 1.51754 & sample48 & run3 & 1.51972 \\
\hline sample06 & run4 & 1.52440 & sample27 & run4 & 1.51756 & sample48 & run4 & 1.51972 \\
\hline sample06 & run5 & 1.52435 & sample27 & run5 & 1.51752 & sample48 & run5 & 1.51973 \\
\hline sample06 & run6 & 1.52441 & sample27 & run6 & 1.51752 & sample48 & run6 & 1.51967 \\
\hline sample06 & run7 & 1.52440 & sample27 & run7 & 1.51755 & sample48 & run7 & 1.51968 \\
\hline sample06 & run8 & 1.52441 & sample27 & run8 & 1.51754 & sample48 & run8 & 1.51966 \\
\hline sample07 & run1 & 1.52024 & sample28 & run1 & 1.51771 & sample49 & run1 & 1.52546 \\
\hline sample07 & run2 & 1.52019 & sample28 & run2 & 1.51771 & sample49 & run2 & 1.52540 \\
\hline sample07 & run3 & 1.52018 & sample28 & run3 & 1.51777 & sample49 & run3 & 1.52541 \\
\hline
\end{tabular}




\begin{tabular}{|c|c|c|c|c|c|c|c|c|}
\hline sample07 & run4 & 1.52019 & sample28 & run4 & 1.51777 & sample49 & run4 & 1.52543 \\
\hline sample07 & run5 & 1.52020 & sample28 & run5 & 1.51762 & sample49 & run5 & 1.52547 \\
\hline sample07 & run6 & 1.52025 & sample28 & run6 & 1.51767 & sample49 & run6 & 1.52537 \\
\hline sample07 & run7 & 1.52025 & sample28 & run7 & 1.51762 & sample49 & run7 & 1.52547 \\
\hline sample07 & run8 & 1.52022 & sample28 & run8 & 1.51768 & sample49 & run8 & 1.52545 \\
\hline sample08 & run1 & 1.52364 & sample29 & run1 & 1.52178 & sample50 & run1 & 1.52539 \\
\hline sample08 & run2 & 1.52364 & sample29 & run2 & 1.52174 & sample50 & run2 & 1.52542 \\
\hline sample08 & run3 & 1.52362 & sample29 & run3 & 1.52179 & sample50 & run3 & 1.52535 \\
\hline sample08 & run4 & 1.52364 & sample29 & run4 & 1.52174 & sample50 & run4 & 1.52538 \\
\hline sample08 & run5 & 1.52365 & sample29 & run5 & 1.52176 & sample50 & run5 & 1.52545 \\
\hline sample08 & run6 & 1.52360 & sample29 & run6 & 1.52182 & sample50 & run6 & 1.52540 \\
\hline sample08 & run7 & 1.52363 & sample29 & run7 & 1.52184 & sample50 & run7 & 1.52537 \\
\hline sample08 & run8 & 1.52363 & sample29 & run8 & 1.52175 & sample50 & run8 & 1.52537 \\
\hline sample09 & run1 & 1.51824 & sample30 & run1 & 1.52178 & sample51 & run1 & 1.52024 \\
\hline sample09 & run2 & 1.51818 & sample30 & run2 & 1.52174 & sample51 & run2 & 1.52022 \\
\hline sample09 & run3 & 1.51818 & sample30 & run3 & 1.52169 & sample51 & run3 & 1.52019 \\
\hline sample09 & run4 & 1.51820 & sample30 & run4 & 1.52181 & sample51 & run4 & 1.52022 \\
\hline sample09 & run5 & 1.51817 & sample30 & run5 & 1.52174 & sample51 & run5 & 1.52024 \\
\hline sample09 & run6 & 1.51826 & sample30 & run6 & 1.52177 & sample51 & run6 & 1.52022 \\
\hline sample09 & run7 & 1.51823 & sample30 & run7 & 1.52176 & sample51 & run7 & 1.52027 \\
\hline sample09 & run8 & 1.51820 & sample30 & run8 & 1.52168 & sample51 & run8 & 1.52023 \\
\hline sample10 & run1 & 1.52370 & sample31 & run1 & 1.52163 & sample52 & run1 & 1.52162 \\
\hline sample10 & run2 & 1.52364 & sample31 & run2 & 1.52163 & sample52 & run2 & 1.52161 \\
\hline sample10 & run3 & 1.52367 & sample31 & run3 & 1.52165 & sample52 & run3 & 1.52168 \\
\hline sample10 & run4 & 1.52369 & sample31 & run4 & 1.52172 & sample52 & run4 & 1.52173 \\
\hline sample10 & run5 & 1.52368 & sample31 & run5 & 1.52171 & sample52 & run5 & 1.52166 \\
\hline sample10 & run6 & 1.52368 & sample31 & run6 & 1.52165 & sample52 & run6 & 1.52169 \\
\hline sample10 & run7 & 1.52367 & sample31 & run7 & 1.52164 & sample52 & run7 & 1.52166 \\
\hline sample10 & run8 & 1.52366 & sample31 & run8 & 1.52169 & sample52 & run8 & 1.52169 \\
\hline sample11 & run1 & 1.51950 & sample32 & run1 & 1.51941 & sample53 & run1 & 1.52060 \\
\hline sample11 & run2 & 1.51946 & sample32 & run2 & 1.51934 & sample53 & run2 & 1.52061 \\
\hline sample11 & run3 & 1.51946 & sample32 & run3 & 1.51939 & sample53 & run3 & 1.52066 \\
\hline sample11 & run4 & 1.51952 & sample32 & run4 & 1.51928 & sample53 & run4 & 1.52069 \\
\hline sample11 & run5 & 1.51949 & sample32 & run5 & 1.51927 & sample53 & run5 & 1.52065 \\
\hline sample11 & run6 & 1.51942 & sample32 & run6 & 1.51942 & sample53 & run6 & 1.52070 \\
\hline sample11 & run7 & 1.51952 & sample32 & run7 & 1.51929 & sample53 & run7 & 1.52057 \\
\hline sample11 & run8 & 1.51947 & sample32 & run8 & 1.51936 & sample53 & run8 & 1.52064 \\
\hline sample12 & run1 & 1.51880 & sample33 & run1 & 1.51869 & sample54 & run1 & 1.51922 \\
\hline sample12 & run2 & 1.51877 & sample33 & run2 & 1.51870 & sample54 & run2 & 1.51924 \\
\hline sample12 & run3 & 1.51875 & sample33 & run3 & 1.51871 & sample54 & run3 & 1.51917 \\
\hline sample12 & run4 & 1.51880 & sample33 & run4 & 1.51879 & sample54 & run4 & 1.51914 \\
\hline sample12 & run5 & 1.51875 & sample33 & run5 & 1.51880 & sample54 & run5 & 1.51919 \\
\hline sample12 & run6 & 1.51876 & sample33 & run6 & 1.51875 & sample54 & run6 & 1.51918 \\
\hline sample12 & run7 & 1.51879 & sample33 & run7 & 1.51878 & sample54 & run7 & 1.51919 \\
\hline sample12 & run8 & 1.51881 & sample33 & run8 & 1.51876 & sample54 & run8 & 1.51915 \\
\hline sample13 & run1 & 1.52369 & sample34 & run1 & 1.52016 & sample55 & run1 & 1.52545 \\
\hline sample13 & run2 & 1.52363 & sample34 & run2 & 1.52014 & sample55 & run2 & 1.52540 \\
\hline sample13 & run3 & 1.52359 & sample34 & run3 & 1.52019 & sample55 & run3 & 1.52542 \\
\hline sample13 & run4 & 1.52367 & sample34 & run4 & 1.52020 & sample55 & run4 & 1.52546 \\
\hline sample13 & run5 & 1.52365 & sample34 & run5 & 1.52019 & sample55 & run5 & 1.52542 \\
\hline sample13 & run6 & 1.52363 & sample34 & run6 & 1.52019 & sample55 & run6 & 1.52544 \\
\hline sample13 & run7 & 1.52357 & sample34 & run7 & 1.52021 & sample55 & run7 & 1.52542 \\
\hline sample13 & run8 & 1.52361 & sample34 & run8 & 1.52017 & sample55 & run8 & 1.52540 \\
\hline sample14 & run1 & 1.51913 & sample35 & run1 & 1.52405 & sample56 & run1 & 1.51927 \\
\hline sample14 & run2 & 1.51910 & sample35 & run2 & 1.52400 & sample56 & run2 & 1.51931 \\
\hline
\end{tabular}




\begin{tabular}{|c|c|c|c|c|c|c|c|c|}
\hline sample14 & run3 & 1.51909 & sample35 & run3 & 1.52411 & sample56 & run3 & 1.51930 \\
\hline sample14 & run4 & 1.51916 & sample35 & run4 & 1.52404 & sample56 & run4 & 1.51925 \\
\hline sample14 & run5 & 1.51912 & sample35 & run5 & 1.52417 & sample56 & run5 & 1.51927 \\
\hline sample14 & run6 & 1.51913 & sample35 & run6 & 1.52403 & sample56 & run6 & 1.51934 \\
\hline sample14 & run7 & 1.51915 & sample35 & run7 & 1.52417 & sample56 & run7 & 1.51934 \\
\hline sample14 & run8 & 1.51918 & sample35 & run8 & 1.52403 & sample56 & run8 & 1.51930 \\
\hline sample15 & run1 & 1.52049 & sample36 & run1 & 1.52041 & sample57 & run1 & 1.51911 \\
\hline sample15 & run2 & 1.52054 & sample36 & run2 & 1.52031 & sample57 & run2 & 1.51922 \\
\hline sample15 & run3 & 1.52046 & sample36 & run3 & 1.52044 & sample57 & run3 & 1.51918 \\
\hline sample15 & run4 & 1.52051 & sample36 & run4 & 1.52031 & sample57 & run4 & 1.51909 \\
\hline sample15 & run5 & 1.52048 & sample36 & run5 & 1.52044 & sample57 & run5 & 1.51918 \\
\hline sample15 & run6 & 1.52053 & sample36 & run6 & 1.52029 & sample57 & run6 & 1.51912 \\
\hline sample15 & run7 & 1.52049 & sample36 & run7 & 1.52043 & sample57 & run7 & 1.51912 \\
\hline sample15 & run8 & 1.52047 & sample36 & run8 & 1.52033 & sample57 & run8 & 1.51911 \\
\hline sample16 & run1 & 1.51895 & sample37 & run1 & 1.52148 & sample58 & run1 & 1.51959 \\
\hline sample16 & run2 & 1.51902 & sample37 & run2 & 1.52145 & sample58 & run2 & 1.51956 \\
\hline sample16 & run3 & 1.51889 & sample37 & run3 & 1.52149 & sample58 & run3 & 1.51957 \\
\hline sample16 & run4 & 1.51901 & sample37 & run4 & 1.52150 & sample58 & run4 & 1.51953 \\
\hline sample16 & run5 & 1.51891 & sample37 & run5 & 1.52145 & sample58 & run5 & 1.51957 \\
\hline sample16 & run6 & 1.51891 & sample37 & run6 & 1.52150 & sample58 & run6 & 1.51951 \\
\hline sample16 & run7 & 1.51899 & sample37 & run7 & 1.52146 & sample58 & run7 & 1.51954 \\
\hline sample16 & run8 & 1.51899 & sample37 & run8 & 1.52149 & sample58 & run8 & 1.51957 \\
\hline sample17 & run1 & 1.51951 & sample38 & run1 & 1.52250 & sample59 & run1 & 1.52167 \\
\hline sample17 & run2 & 1.51954 & sample38 & run2 & 1.52249 & sample59 & run2 & 1.52161 \\
\hline sample17 & run3 & 1.51949 & sample38 & run3 & 1.52245 & sample59 & run3 & 1.52162 \\
\hline sample17 & run4 & 1.51953 & sample38 & run4 & 1.52255 & sample59 & run4 & 1.52166 \\
\hline sample17 & run5 & 1.51949 & sample38 & run5 & 1.52255 & sample59 & run5 & 1.52166 \\
\hline sample17 & run6 & 1.51944 & sample38 & run6 & 1.52247 & sample59 & run6 & 1.52167 \\
\hline sample17 & run7 & 1.51952 & sample38 & run7 & 1.52249 & sample59 & run7 & 1.52167 \\
\hline sample17 & run8 & 1.51950 & sample38 & run8 & 1.52247 & sample59 & run8 & 1.52158 \\
\hline sample18 & run1 & 1.52437 & sample39 & run1 & 1.51922 & sample60 & run1 & 1.51958 \\
\hline sample18 & run2 & 1.52440 & sample39 & run2 & 1.51925 & sample60 & run2 & 1.51958 \\
\hline sample18 & run3 & 1.52442 & sample39 & run3 & 1.51920 & sample60 & run3 & 1.51952 \\
\hline sample18 & run4 & 1.52439 & sample39 & run4 & 1.51916 & sample60 & run4 & 1.51952 \\
\hline sample18 & run5 & 1.52440 & sample39 & run5 & 1.51921 & sample60 & run5 & 1.51954 \\
\hline sample18 & run6 & 1.52438 & sample39 & run6 & 1.51924 & sample60 & run6 & 1.51956 \\
\hline sample18 & run7 & 1.52434 & sample39 & run7 & 1.51922 & sample60 & run7 & 1.51956 \\
\hline sample18 & run8 & 1.52436 & sample39 & run8 & 1.51915 & sample60 & run8 & 1.51956 \\
\hline sample19 & run1 & 1.51877 & sample40 & run1 & 1.51825 & sample61 & run1 & 1.52038 \\
\hline sample19 & run2 & 1.51875 & sample40 & run2 & 1.51824 & sample61 & run2 & 1.52044 \\
\hline sample19 & run3 & 1.51879 & sample40 & run3 & 1.51827 & sample61 & run3 & 1.52044 \\
\hline sample19 & run4 & 1.51879 & sample40 & run4 & 1.51827 & sample61 & run4 & 1.52045 \\
\hline sample19 & run5 & 1.51874 & sample40 & run5 & 1.51827 & sample61 & run5 & 1.52039 \\
\hline sample19 & run6 & 1.51877 & sample40 & run6 & 1.51821 & sample61 & run6 & 1.52044 \\
\hline sample19 & run7 & 1.51871 & sample40 & run7 & 1.51816 & sample61 & run7 & 1.52045 \\
\hline sample19 & run8 & 1.51872 & sample40 & run8 & 1.51819 & sample61 & run8 & 1.52043 \\
\hline sample20 & run1 & 1.51043 & sample41 & run1 & 1.52056 & sample62 & run1 & 1.52339 \\
\hline sample20 & run2 & 1.51039 & sample41 & run2 & 1.52054 & sample62 & run2 & 1.52333 \\
\hline sample20 & run3 & 1.51038 & sample41 & run3 & 1.52054 & sample62 & run3 & 1.52337 \\
\hline sample20 & run4 & 1.51040 & sample41 & run4 & 1.52049 & sample62 & run4 & 1.52334 \\
\hline sample20 & run5 & 1.51045 & sample41 & run5 & 1.52052 & sample62 & run5 & 1.52334 \\
\hline sample20 & run6 & 1.51040 & sample41 & run6 & 1.52050 & sample62 & run6 & 1.52337 \\
\hline sample20 & run7 & 1.51041 & sample41 & run7 & 1.52053 & sample62 & run7 & 1.52336 \\
\hline sample20 & run8 & 1.51040 & sample41 & run8 & 1.52052 & sample62 & run8 & 1.52336 \\
\hline sample21 & run1 & 1.52169 & sample42 & run1 & 1.52063 & sample63 & run1 & 1.52336 \\
\hline
\end{tabular}




\begin{tabular}{|l|l|l|l|l|l|l|l|l|} 
sample21 & run2 & 1.52172 & sample42 & run2 & 1.52058 & sample63 & run2 & 1.52340 \\
\hline sample21 & run3 & 1.52175 & sample42 & run3 & 1.52070 & sample63 & run3 & 1.52338 \\
\hline sample21 & run4 & 1.52171 & sample42 & run4 & 1.52065 & sample63 & run4 & 1.52330 \\
\hline sample21 & run5 & 1.52178 & sample42 & run5 & 1.52060 & sample63 & run5 & 1.52337 \\
\hline sample21 & run6 & 1.52171 & sample42 & run6 & 1.52061 & sample63 & run6 & 1.52336 \\
\hline sample21 & run7 & 1.52173 & sample42 & run7 & 1.52068 & sample63 & run7 & 1.52333 \\
\hline sample21 & run8 & 1.52169 & sample42 & run8 & 1.52061 & sample63 & run8 & 1.52338 \\
\hline
\end{tabular}




\section{$\underline{\text { Appendix B }}$}

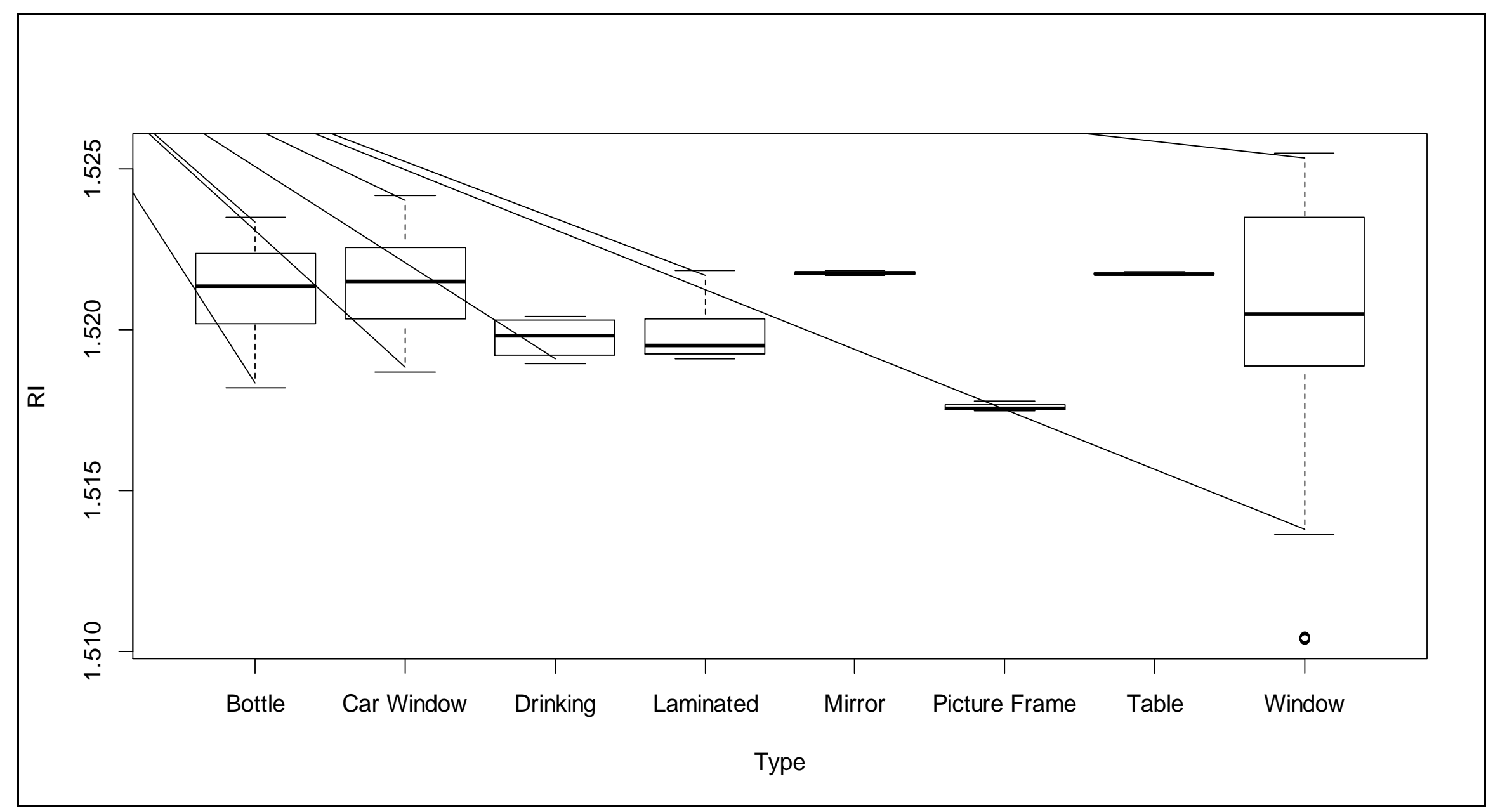




\section{$\underline{\text { References }}$}

1. $\quad$ Saferstein R. Forensic Science Handbook. 2002; Volume 1:161-213.

2. Duckworth Douglas C. SJM, Charles K. Bayne, Robert D. Koons, Shirly

Montero, and Jose R. Almirall. Forensic glass analysis by ICP-MS: a multi-element assessment of discriminating power via analysis of variance and pairwise comparisons. Journal of Analytical Atomic Spectrometry. 2002;17:662-8.

3. Trejos T, Almirall JR. Sampling strategies for the analysis of glass fragments by LA-ICP-MS: Part I. Micro-homogeneity study of glass and its application to the interpretation of forensic evidence. Talanta. 2005;67(2):388-95.

4. Committee on Identifying the Needs of the Forensic Sciences Community NRC. Strengthening Forensic Science in the United States: A Path Forward. National Academy of Sciences. 2009.

5. (SWGMAT) SWGfMA. Glass Refractive Index Determination. Forensic Science Communications. 2005;7(1):1-10.

6. Newton AWN, Curran JM, Triggs CM, Buckleton JS. The consequences of potentially differing distributions of the refractive indices of glass fragments from control and recovered sources. Forensic Science International. 2004;140(2-3):185-93.

7. Hicks T, Monard Sermier F, Goldmann T, Brunelle A, Champod C, Margot P. The classification and discrimination of glass fragments using non destructive energy dispersive X-ray [mu]fluorescence. Forensic Science International. 2003;137(2-3):10718.

8. Howden CR, Dudley RJ, Smalldon KW. The Analysis of Small Glass Fragments Using Energy Dispersive X-Ray Fluorescence Spectrometry. Journal of the Forensic Science Society. 1978;18(1-2):99-112.

9. Jembrih-Simburger D, C. Neelmeijer, O. Schalm, P. Fredrickx, M. Schreiner, K. De Vis, M. Mader, D. Schryvers, and J. Caen. The colour of silver stained glassanalytical investigations carried out with XRF, SEM/EDX, TEM, and IBA. Journal of Analytical Atomic Spectrometry. 2002;17:321-8.

10. Laskin A, and James P. Cowin. Automated Single-Particle SEM/EDX Analysis of Submicrometer Particles down to 0.1 Micrometers. Journal of Anal Chemistry. 2001;73(5):1023-9.

11. Trejos T, Almirall JR. Sampling strategies for the analysis of glass fragments by LA-ICP-MS: Part II: Sample size and sample shape considerations. Talanta. 2005;67(2):396-401.

12. Robert D. Koons JB. Distribution of Refractive Index Values in Sheet Glass. Forensic Science Communications. 2001;3(1).

13. Bennett RL, Kim ND, Curran JM, Coulson SA, Newton AWN. Spatial variation of refractive index in a pane of float glass. Science \&amp; Justice. 2003;43(2):71-6.

14. BIMP, IEC, IFCC, ISO, IUPAC, IUPAP, et al. Guide to the expression of uncertainty in measurement. ISO. 1995.

15. Taylor BN, Kuyatt CE. Guidelines for Evaluating and Expressing the Uncertainty of NIST Measurement Results. NIST Technical Note 1297. 1994. 
16. Kucera J, Bode P, Stepanek V. The 1993 ISO Guide to the expression of uncertainty in measurement applied to NAA. Journal of Radioanalytical and Nuclear Chemistry. 2000;245(1):115-22.

17. Haslam SA, McGarty C. A 100 years of certitude? Social psychology, the experimental method and the management of scientific uncertainty. British Journal of Social Psychology. 2001;40:1-21.

18. Gustavo González A, Ángeles Herrador M. A practical guide to analytical method validation, including measurement uncertainty and accuracy profiles. TrAC Trends in Analytical Chemistry. 2007;26(3):227-38.

19. Garvin EJ, Koons RD. Evaluation of Match Criteria Used for the Comparison of Refractive Index of Glass Fragments* $, \dagger, \ddagger, \S$. Journal of Forensic Sciences.

2011;56(2):491-500. 